\title{
Aprendizagem pela cooperação no Programa UCA: percepção dos professores a partir de Projetos de Aprendizagem
}

\author{
Aline Silva de Bona - IFRS-LEC/PPGIE/UFRGS - vivaexatas@ yahoo.com.br \\ Eduardo Britto Velho de Mattos - CAp/LEC/PPGIE/UFRGS - eduardo.britto@ufrgs.br \\ Marlusa Benedetti da Rosa - CAp/LEC/PPGIE/UFRGS - marlusa.benedetti@ufrgs.br \\ Cristina Maria Pescador - UCS-LEC/PPGIE/UFRGS - cpescador@ gmail.com \\ Léa da Cruz Fagundes - LEC/PPGIE/UFRGS - leafagun@ufrgs.br \\ Marcus Vinicius de Azevedo Basso - IM/LEC/PPGEMAT/UFRGS - mbasso@ufrgs.br
}

\begin{abstract}
Resumo: $O$ presente estudo consiste na análise de relatos de experiências baseados nos depoimentos de professores a respeito de sua prática com Projetos de Aprendizagem desenvolvidos dentro do projeto um computador por aluno - UCA, em uma escola de educação básica no Estado do Rio Grande do Sul, durante os anos de 2010 e 2011. Os relatos são analisados à luz da teoria de Piaget, em especial em relação a Projetos de Aprendizagem e ao uso de tecnologias digitais como recursos de colaboração para contemplar a inclusão da escola na Cultura Digital. O método desta investigação é o estudo de caso, e tem como objetivo analisar o envolvimento de professores e estudantes no UCA e as potencialidades propiciadas pelo seu uso.

Palavras- Chaves: Um Computador por Aluno (UCA), Projetos de Aprendizagem, Tecnologia Digital

\section{Cooperative Learning in the Brazilian One Laptop per Student Program: teachers' perception from the point of view of Learning Projects}

\begin{abstract}
This paper analyzes a few experiences reported by a group of teachers on their work based on learning projects were developed in the Brazilian version of the Project One Laptop per Child (UCA) in an elementary and secondary school in the state of Rio Grande do Sul in 2010. The statements are analyzed at the light of Piagetian concepts, especially how they can be related to Learning Projects and the use of digital technologies as collaborative resources used towards including school in the Digital Culture. The methodology was carried out as a case study and the main goal is to analyze teachers' and students' engagement in Projeto UCA, and the potentiality of them being used.
\end{abstract}

Keywords: One Laptop per Child (UCA), Learning Projects, Digital Technologies

\section{Introdução}

A qualidade da educação brasileira, além de ser assunto recorrente nos meios de comunicação, é uma preocupação constante no meio acadêmico. Muitas universidades, através de parcerias com as escolas das mais variadas esferas públicas, discutem e investigam estratégias, métodos e procedimentos que, baseados em recursos variados, promovam a aprendizagem dos estudantes durante todo o período escolar exigido por lei. Paralelamente, algumas políticas públicas revelam-se interessadas em auxiliar e investir na melhoria da educação do país, como, por exemplo, o Plano de Desenvolvimento da Educação (PDE), em que o governo federal estabeleceu como meta a qualificação da educação nacional. Nesse contexto, surgem programas que buscam efetivar a inclusão da escola na Cultura Digital, como o Programa Um Computador por Aluno (UCA), conhecido em suas duas fases iniciais como Projeto UCA. 


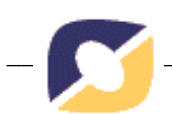

Vê-se, atualmente, que as Tecnologias Digitais (TDs) fazem parte da vida cotidiana da sociedade e, em particular, de professores e alunos. No entanto, de acordo com Soares et al. (2011) a Cultura Digital, entendida como aquelas manifestações sociais, em que as relações humanas são mediadas por TDs e Tecnologias da Informação e Comunicação (TICs), parece ainda estar procurando seu caminho para fazer parte das práticas escolares. Nesse sentido, acreditamos que os recursos digitais podem ser explorados na escola e que as suas contribuições justificam a opção do professor em usá-los com o objetivo de promover e qualificar a aprendizagem dos estudantes. Nessa perspectiva, pesquisas como as de Bona (2010) mostram que o uso das TDs em sala de aula mobiliza os alunos a aprender a aprender segundo sua curiosidade. Além disso, estudos apontam que o desenvolvimento de Projetos de Aprendizagem (PAs) por alunos da educação básica, a partir de investigações do seu interesse, possibilita que se observem aprendizagens conceituais que superam os conteúdos tradicionalmente planejados pelo professor. Nesse sentido, Mattos (2010, p.42) destaca que as perguntas iniciais propostas pelos alunos nos seus PAs "geralmente extrapolam o cunho disciplinar, fugindo, assim, das suas amarras e dos seus assuntos e conteúdos sequenciais e previamente definidos" e, ao analisar as aprendizagens de grupos de alunos, concluiu que os conceitos de matemática que derivaram dos seus Projetos de Aprendizagem superaram a listagem curricular tradicionalmente aceita e esperada ${ }^{1}$.

O presente estudo pretende colaborar com reflexões a respeito da prática docente, considerando-se a ideia de colaboração e cooperação como formas de aprendizagem dos alunos, na concepção construtivista. Para tanto, apresentamos, inicialmente, o contexto do Projeto e do Programa UCA, acompanhado de breves fundamentos teóricos sobre PAs. Em seguida, tecemos algumas considerações sobre os conceitos de colaboração e cooperação, de acordo com a teoria psicogenética de Jean Piaget e, por fim, apresentamos um estudo de caso sobre as reflexões de professores que atuam na escola observada e nos PAs inseridos no UCA.

\section{Breve Contexto: Programa UCA e Projetos de Aprendizagem}

O Programa $\mathrm{UCA}^{2}$ se propõe a ampliar e efetivar o processo de inclusão da escola na Cultura Digital, oferecendo laptops educacionais a professores e estudantes da educação básica. Com ele, e através do uso pedagógico das TICs, pretende-se criar e socializar novas formas de utilização das TDs.

Na primeira fase piloto do projeto, em 2007, participaram apenas cinco escolas brasileiras situadas nas seguintes cidades: Porto Alegre/RS, São Paulo/SP, Palmas/TO, Pirai/RJ e Brasília/DF. Nessa fase, os laptops foram obtidos através de doação e possuíam funcionalidades e sistemas operacionais diferentes. Na segunda fase, iniciada em 2010, foram adquiridos e distribuídos pelo Ministério da Educação um milhão e meio de laptops. Neste momento, as escolas participantes receberam também os demais equipamentos necessários para conexão dos laptops com a internet (servidores, acesso a banda larga, roteadores para cada sala de aula); um curso de formação pedagógica e apropriação tecnológica, o qual foi disponibilizado para professores e gestores, contando com o apoio das Secretarias Estaduais e Municipais de Educação, através dos Núcleos de Tecnologia Estadual (NTEs) e Núcleos Municipais de Tecnologia (NTMs); e o suporte de equipes de pesquisadores de universidades federais ${ }^{3}$, em parceria com outras instituições de ensino superior, conforme a localização das escolas.

Atualmente, participam do programa cerca de 400 escolas $^{4}$ públicas brasileiras (municipais, estaduais e federais) distribuídas nas diversas regiões do país. Nesse cenário, é interessante problematizar o processo vivenciado pelas diferentes instituições, 


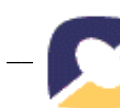

com o objetivo de compreender os avanços em termos conceituais e pedagógicos no que diz respeito a inclusão digital que se espera promover.

No Rio Grande do Sul, 24 escolas públicas fazem parte do UCA, dentre as quais selecionamos uma instituição para este estudo de caso.

\title{
2.1 Um Computador por Aluno X Um Computador para Muitos
}

Entende-se que a chegada dos laptops às diferentes instituições gerou alterações na rotina escolar, em especial acelerando a integração da escola na Cultura Digital. A presença dos laptops na sala de aula, por si só, pode ser considerada um momento de desequilíbrio na rotina e cultura escolar e nos conhecimentos de professores e estudantes sobre ela, isso porque

\begin{abstract}
o conhecimento não é um produto fixo e acabado. Ele é construído num contexto de troca, mediante um tensionamento constante entre o conhecimento atual (certezas atuais, provisórias) e as dúvidas que recaem sobre essas certezas, conduzindo ao estabelecimento de novas relações ou conhecimentos (novas certezas, ainda que temporárias). (Nevado et al., 2007, p. 29).
\end{abstract}

Assim, considerando-se que o conhecimento está sempre em construção e que o dispositivo midiático ${ }^{5}$ age ao mesmo tempo sobre os atores e sobre os saberes envolvidos na aprendizagem, pode-se pensar que se trata de uma recontextualização das práticas e das relações. As pesquisas de Alava (2002, p. 62) indicam que "os dispositivos midiatizados são fortes reorganizadores das relações pedagógicas e das escolhas didáticas". Acredita-se que, utilizando as TICs, os professores poderão compartilhar informações, experiências e saberes com professores de diferentes escolas, regiões e países.

Nesse sentido, na modalidade "um computador por aluno" (ou "um para um", ou modalidade 1:1), o tempo e o espaço da sala de aula adquirem outra dimensão. Enquanto no modelo de laboratório (um para muitos), o uso dos equipamentos é feito em regime compartilhado, exigindo agendamento e planejamento prévio de atividades, o modelo um para um permite a utilização concomitante por todos os alunos e professores na escola. Além disso, a portabilidade dos equipamentos permite a utilização em atividades em diversos ambientes e contextos escolares.

No modelo um para muitos os alunos precisavam se deslocar para o laboratório de informática da escola e, na maioria das vezes, o professor responsável pelo laboratório era quem desenvolvia os trabalhos solicitados pelos professores regentes. A chegada dos laptops conectados à rede modifica totalmente esse cenário. Com a possibilidade de os alunos conectarem-se ao mundo, aliada à necessidade de aprenderem a explorá-lo e qualificá-lo, são ultrapassadas as paredes da escola. Junto a essa mudança de paradigma, é possível acreditar que o UCA se constitua também em um disparador para o rompimento com métodos de ensino centrados na transmissão e fragmentação do conhecimento.

$\mathrm{Na}$ modalidade um para muitos, a dinâmica de compartilhamento do espaço, associada ao número limitado de máquinas, leva ao desenvolvimento de atividades muitas vezes desvinculadas da proposta pedagógica. Por outro lado, com o laptop em sala de aula, a tecnologia pode atender a demandas do momento e o laptop passa a ser um recurso versátil e disponível. De acordo com Fagundes (1992), a inovação não é apenas a Cultura Digital, com a TD, mas o leque de possibilidades que ela abre. Por essa razão, o fundamental para a inclusão digital não é o laptop em si, nem a possibilidade de acesso à rede, mas o uso que se fará desse acesso e o novo papel que 


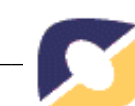

alunos e professores assumirão frente a esse recurso, o que configura a Cultura Digital, de acordo com Hoffmann e Fagundes (2008).

\subsection{Projetos de Aprendizagem}

Conforme Fagundes et al. (1999), é necessário que exista uma efetiva integração entre a TD e o currículo escolar, com as diferentes áreas do conhecimento que o compõem. Nesse sentido, o currículo e o plano político-pedagógico que constituem e sustentam a estrutura da escola precisam ser repensados. É fundamental que a escola se torne um espaço onde todos sejam interagentes: um ambiente em que alunos e professores assumam papeis de coautores no processo de aprendizagem.

Com a inserção das TICs na sala de aula, em especial com a chegada do UCA, a necessidade de propor novas maneiras de ensinar, aprender e construir currículos passou a ser debatida com maior intensidade. Prado (2005), por exemplo, sugere que as TDs sejam integradas ao trabalho com projetos nos quais o aluno é o sujeito ativo da aprendizagem. Para a autora, ao desenvolver projetos, o professor pode criar situações que provoquem a interação entre os alunos, orientando-os a: aprender a fazer, formular perguntas, testar ideias, experimentar e aplicar conhecimentos e buscar diálogo com especialistas, construindo seu conhecimento e seu perfil de investigador.

Nesse sentido, o desenvolvimento de PAs como proposta pedagógica possibilita ao aluno a construção de conhecimentos a partir da investigação. Segundo Prado (2005, p.13), "na pedagogia de projetos, o aluno aprende no processo de produzir, levantar dúvidas, pesquisar e criar relações que incentivam novas buscas, descobertas, compreensões e reconstruções de conhecimento."

Com os PAs, o aluno passa a ser o foco central do processo de aprendizagem e o professor assume a função de orientador, com o objetivo de estimular e auxiliar na busca e organização de informações, o estabelecimento de relações entre as investigações, os conceitos estudados e as dúvidas e certezas dos alunos.

Prado (2005) destaca, ainda, que o trabalho por projetos requer mudanças na postura do professor e nas concepções epistemológicas de como se dá o processo de ensino e aprendizagem. Para a autora, existem

três aspectos fundamentais que o professor precisa considerar para trabalhar com projetos: as possibilidades de desenvolvimento de seus alunos; as dinâmicas sociais do contexto em que atua e as possibilidades de sua mediação pedagógica.(p.13)

Uma orientação a alunos que desenvolvem PAs - na perspectiva de efetivar a inclusão da escola na Cultura Digital, a integração das TDs ao currículo escolar e promover a interdisciplinaridade - requer que o professor busque compreender e acompanhar o processo de aprendizagem e os caminhos percorridos pelos seus alunos, em especial procure conhecer as suas certezas e dúvidas e planeje intervenções que os levem a investigar conceitos de diversas áreas do conhecimento. Requer também que o professor consiga quebrar alguns paradigmas de sua formação inicial, assumindo uma postura em que o foco da aprendizagem esteja nas ações dos alunos, ao contrário das aulas expositivas cujo foco está centrado no professor.

$\mathrm{Na}$ proposta de aprendizagem por projetos, com Fagundes et al. (1999), as investigações surgem de genuínas curiosidades e dúvidas dos alunos sobre o mundo e a realidade na qual estão inseridos. Os PAs têm início com a formulação, pelos alunos, de "questões de investigação, as quais passam a constituir e compor a base curricular da 


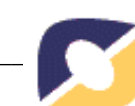

escola e - em especial - dos alunos envolvidos com os referidos projetos e suas consequentes pesquisas e aprendizagens" (Mattos, 2010 p.41).

Segundo Pires (2004), os projetos abrem novas perspectivas interdisciplinares na medida em que, a partir dos temas, busca-se o estabelecimento de relações com outros assuntos, tanto relacionados às disciplinas quanto fora delas. Todas as disciplinas participantes do processo, representadas pelos professores especialistas das diferentes áreas do conhecimento, influenciam e são influenciadas pelas outras restabelecendo novas unidades de conhecimento. Ou seja, dos PAs emerge "um novo modelo de saber, o qual não está mais na tradição do que se sabe, mas na procura do que não se sabe." (Aires, 2011 p. 217).

Nesse sentido, destaca-se que as perguntas propostas pelos alunos não precisam tratar dos assuntos previamente explorados pelas disciplinas escolares, pelo contrário, elas podem extrapolar o cunho disciplinar, fugindo das suas amarras e dos seus conteúdos sequenciais e pré-definidos. Facilitando a efetivação de uma orientação interdisciplinar que possibilite a integração das TDs com as diversas áreas do conhecimento.

Cabe observar, por fim, que a aprendizagem por projetos integra-se à Cultura Digital e opõe-se ao ensino por projetos, no qual as decisões partem do professor, tendo com base o currículo previamente estabelecido e a sua proposta de trabalho. A aprendizagem por projetos refere-se à possibilidade da construção de conhecimento pelo sujeito "em interação com o meio, com os outros sujeitos e com os objetos de conhecimento de que ele deseje apropriar-se" (Fagundes et al., 1999, p. 16). Ainda, segundo as autoras, na aprendizagem por projetos, o aluno se movimenta a partir de seu conhecimento prévio e passa a "interagir com o desconhecido, ou com novas situações, para se apropriar do conhecimento específico - seja nas ciências, nas artes, na cultura tradicional, ou na cultura em transformação" (p. 16).

\section{Colaboração e Cooperação como Formas de Aprendizagem}

Os termos colaboração e cooperação - ainda que sejam usados com variados significados na escola - serão analisadas neste estudo, com base na epistemologia genética de Piaget, como formas de aprendizagem.

Com base na pesquisa de Bona et al. (2011), é possível refletir sobre as conceituações usualmente adotadas na área da Informática na Educação, e assim diferenciar os conceitos de colaboração e cooperação considerando que as ações de colaboração são entendidas como a comunicação entre pessoas que trabalham juntas e com um mesmo objetivo; e as ações de cooperação compreendem a comunicação em que não existe mais o conceito de indivíduo, apenas o de grupo.

Piaget (1973) indica que colaborar "resume-se à reunião das ações que são realizadas isoladamente pelos parceiros, mesmo quando o fazem na direção de um objetivo" (p. 81) e que "cooperar na ação é operar em comum, isto é, ajustar por meio de novas operações (qualitativas ou métricas) de correspondência, reciprocidade ou complementaridade, as operações executadas por cada um dos parceiros." (p.105). Piaget destaca, ainda, que cooperar constitui um sistema de operações que permitem ajustar as operações umas às outras. Essas operações individuais constituem um sistema de ações descentradas e podem ser coordenadas devido aos agrupamentos de operações de outros, como se fossem próprias.

O termo ajustar utilizado por Piaget é essencial para diferenciar cooperação de colaboração. Quando as ações dos alunos são ajustadas umas às outras (ou seja, aquilo já realizado pelo colega, com base em argumentações, é aceito ou refutado) estão ocorrendo reflexionamentos. Desse modo, a cada interação cooperativa ocorre uma 
mudança de patamar do reflexionamento a um nível mais elevado. Cada reflexão se constitui em uma nova abstração reflexionante, que de um conteúdo viabiliza nova forma, e assim sucessivamente, até se conceber uma abstração refletida, ou seja, uma abstração reflexionante com tomada de consciência.

Nesse sentido, observa-se que é sugerido proporcionar aos alunos meios para que aprendam de modo cooperativo, como exemplificado por Bona et al. (2011) no Espaço de Aprendizagem Digital da Matemática, definido por estes autores. A teoria de Piaget traz subsídios e as tecnologias digitais viabilizam ao professor ações que privilegiem a cooperação, como nos apresenta a pesquisa com Portfólios de Matemática, de Bona (2010). A autora mostra que as tecnologias digitais contextualizam a matemática e também proporcionam um aprender a aprender coletivos entre todos os alunos, tendo em vista que cada um coopera com diferentes ações até a atividade ser compreendida por todos, inclusive pela professora, quando se vê diante de recursos digitais que desconhece e cujos mistérios desvenda graças à ação cooperativa dos alunos.

Pode-se entender, ainda, o conceito de colaboração para Piaget (1973) como uma interação com trocas de pensamento sem ocorrer operações racionais, 0 pensamento pode se dar por comunicação verbal, por coordenações de ponto de vistas e discussões, por exemplo. A colaboração, então, é anterior à cooperação. Por sua vez, a cooperação pode ser compreendida como uma interação que requer a formação de vínculos e de reciprocidade afetiva entre os sujeitos do processo de aprendizagem. Essas interações são interindividuais e possibilitam a modificação do sujeito na sua estrutura cognitiva e do grupo como um todo, como um sistema de interações - e não somente somativa - que possibilita a construção de conhecimento.

Para Piaget, a cooperação é um processo mais elaborado do que a colaboração, no entanto as duas são reconhecidas como formas de aprender. Dentro da concepção construtivista, naqueles trabalhos em que cada aluno faz a sua parte e não visualiza e participa do todo, ocorre apenas uma simples colaboração de partes. A aprendizagem, então, foi apenas de uma parte e não de todo o trabalho proposto.

Neste artigo, apresentam-se os caminhos iniciais da investigação que trata da questão: como potencializar a aprendizagem baseada na cooperação e no desenvolvimento de Projetos de Aprendizagem no contexto do UCA?

A seguir, são expostas algumas "falas" de professores que indicam o desafio de repensar essa educação na Cultura Digital a partir da chegada dos laptops na escola e apontam caminhos para essa investigação.

\section{Estudo de Caso: Projeto de Iniciação Científica no UCA: com a palavra, os professores}

Foram destacadas, para este estudo de caso, algumas "falas" dos professores em fórum virtual ${ }^{6}$ e seus depoimentos em relação ao UCA e ao desenvolvimento de Projetos de Aprendizagem (também denominados, neste contexto, de Projetos de Iniciação Científica) desenvolvidos em todas as séries do Ensino Fundamental na instituição em que este estudo está focado.

Apresentamos um recorte das "falas" de diferentes professores - que retratam a moda das manifestações -, identificados pelas letras A, B, C, D e E, seguidas de respectivas reflexões. Destaca-se que o referido fórum focava uma socialização, com o objetivo de registrar o primeiro contato dos alunos com o laptop e conhecer o processo nos diferentes contextos da escola. 


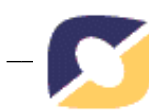

A: A primeira experiência foi mágica. Os alunos ficaram encantados com o UCA mostrando entusiasmados o que iam descobrindo para as professoras. Muitos alunos já sabem seus números de cor e ajudam bastante na distribuição dos laps.

$\mathrm{Na}$ fala do professor A, percebe-se o encantamento dos alunos com o laptop do UCA, sendo um primeiro elemento para mobilizar o processo de aprender a aprender de cada estudante, segundo Bona (2010), e ainda a apropriação tecnológica de cada aluno, já que "decorar seu número" possibilitava maior agilidade na busca pelo laptop e, portanto, permitia a ampliação do seu tempo de uso.

B: Desde que se deu início o uso dos UCAs em sala de aula, o projeto PIXEL, conseguiu caminhar melhor e com excelentes produções por parte dos alunos. O Pixel 70 o tema é nutrição, tipos, distúrbios alimentares, doenças, enfim uma gama imensa de assuntos, por meio dos UCAs, o trabalho esta rendendo frutos, pois é partilhado por todos os integrantes, o que facilita e muito o trabalho dos tutores. $O$ desempenho dos alunos tem me surpreendido, colaboração, ajuda, integração.

$\mathrm{O}$ professor B destaca elementos importantes, e que indicam a incorporação do modelo da Cultura Digital, possibilitados pelo projeto Pixel no contexto do UCA como: colaboração, ajuda e integração. No entanto, a simples leitura da sua reflexão não evidencia a sua compreensão de tais conceitos. Por outro lado, a análise do material dos estudantes (ilustrados nas figuras 1 e 2), indica que os professores priorizam que inicialmente haja colaboração, ou seja, todos se ajudem, cada qual com sua especificidade, e, na sequência os estudantes cooperem para construir a investigação do projeto Pixel. Assim, cada um tem a mesma especificidade e todos trabalham ao mesmo tempo e no mesmo espaço para construir o trabalho que é do grupo. Para que isso aconteça, ocorrem relações complementares, de reciprocidade, e outra coordenação de ações, sendo exatamente o que Piaget (1973) define como um processo de aprendizagem em cooperação.

Comments (3)

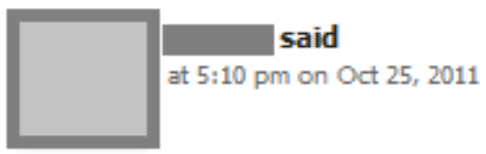

OBS: Tua colega $\downarrow$ tem um jeito bem bacana de organizar a wiki!

Dá uma espiada e pede ajuda para ela!

http:/ pbworks.com

A N organizou de outro jeito, olha só:

http: pbworks.com

Podes deixar a página com a "tua cara"!!!!

Figura 1 - Recorte da orientação de um professor ao sugerir a interação entre alunos 


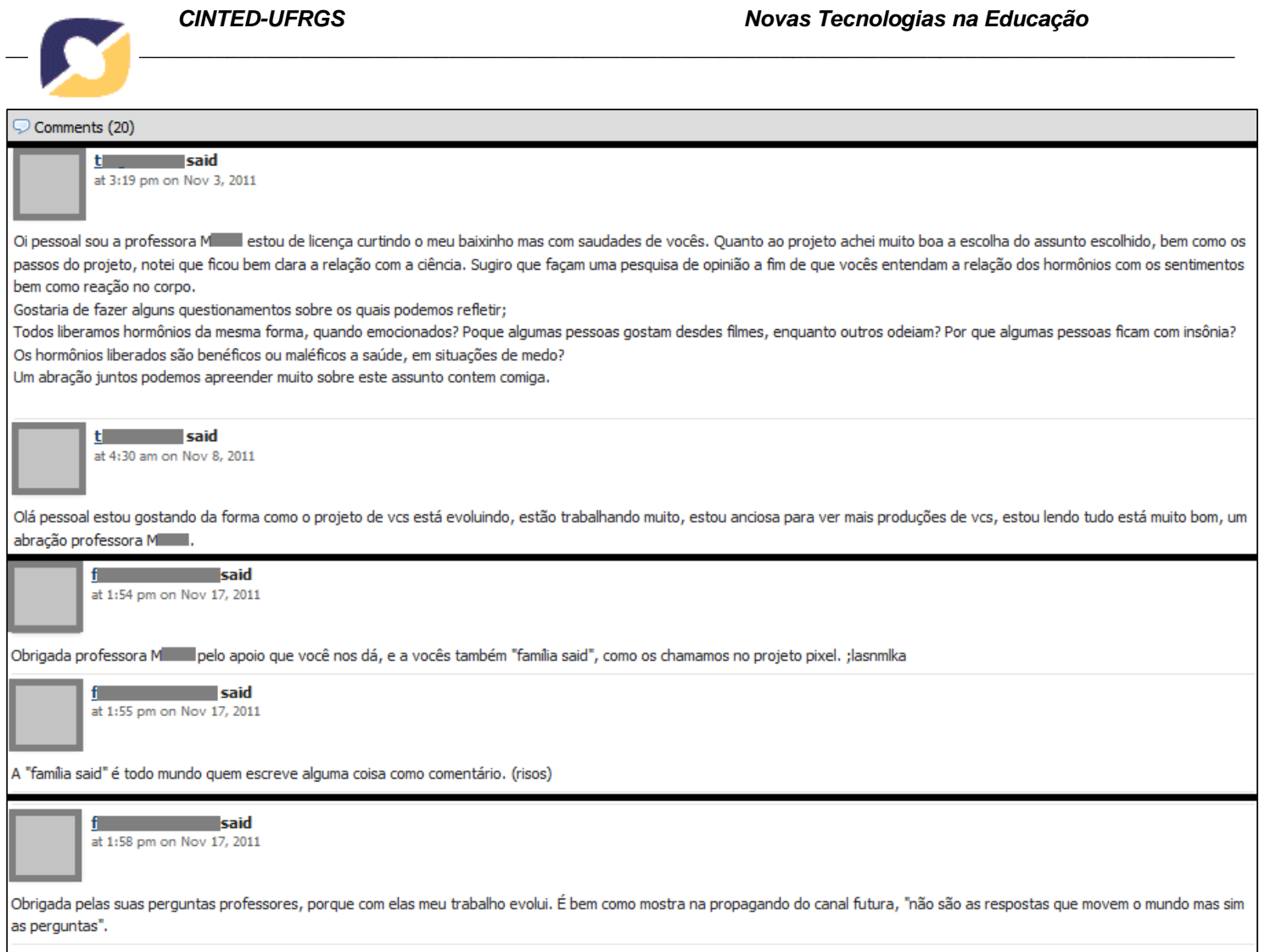

Figura 2 - Recorte da interação entre professores e alunos durante o desenvolvimento de PAs

C: O UCA tem sido uma ferramenta importante nas aulas de Projetos. Os alunos têm conseguido realizar pesquisas na internet e editar seus textos individualmente, sem ter que esperar o rodízio de computadores no Lab. de Informática.

$\mathrm{O}$ depoimento do professor $\mathrm{C}$ evidencia alguns benefícios da modalidade $1: 1$, e mostra a sua necessidade para possibilitar o bom andamento dos trabalhos em uma escola integrada na Cultura Digital e com o desenvolvimento de PAs. Observa-se, também, a apropriação tecnológica de cada aluno com seu laptop e a necessidade de que os equipamentos estejam conectados à Internet para que seja intensificada a colaboração e, em algumas situações, estendida ao nível da cooperação.

D: Acredito que a criação de "workspaces" é uma forte aliada do professor, pois facilita o acesso aos materiais produzidos pelos alunos, além de permitir que os próprios alunos interajam entre si através do mundo digital.

No registro do professor D, observa-se que a interação entre os estudantes é apontada pelo professor como um aspecto importante para a aprendizagem. Além disso, nota-se que o professor passa a ter acesso e conhecer as produções dos seus estudantes, bem como ambos apropriam-se dos recursos tecnológicos disponíveis. Nesse caso, o "workspaces", que entende como aliado do professor para acessar as produções dos estudantes, são as ferramentas disponibilizadas pelo PBworks (http://pbworks.com). Emerge da fala deste professor a evidência de que o PBworks favorece a colaboração entre alunos e professores, e suscita a dúvida sobre a perspectiva dos professores participantes do projeto UCA quanto à possibilidade de utilização desses ambientes como espaço de aprender pela cooperação.

E: Os alunos fizeram as peças da campanha, postaram no Blog, que eles produziram. Esse trabalho será apresentado para todos os alunos e professores do projeto pixel. Para os professores que tiverem o interesse de visualizar o trabalho dos alunos, é só acessar o endereço [...] 


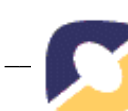

É interessante que o professor E destaca a ação dos estudantes: fizeram, postaram, construíram; e ainda menciona que os trabalhos serão apresentados a todos os alunos e professores do projeto Pixel. Essa produção indica também que o professor considera fundamental a socialização de ideias e conhecimentos. De fato, como depreendido dos capítulos anteriores, essa estratégia - desenvolvimento de PAs, utilização de TDs e ações de socialização, com vista a colaboração e a cooperação promove a aprendizagem.

As análises iniciais sobre as produções dos professores da escola estudada permitem a observação de indicativos sobre a aceitação do UCA, por parte de professores e alunos, bem como da apropriação tecnológica dos estudantes e a inclusão da escola na Cultura Digital. Além disso, é visível a contribuição do uso dos laptops conectados à Internet para o desenvolvimento de PAs, em especial como meio de pesquisa, facilitador da comunicação entre alunos e professores e instrumento que fornece variadas formas de produção.

\section{Considerações Finais}

Vale destacar, inicialmente, que as observações feitas sobre os trabalhos e reflexões de professores a respeito do uso de laptops educacionais, mostram indícios quanto à possibilidade de potencializar a aprendizagem de alunos da educação básica através da cooperação e do desenvolvimento de PAs no contexto do UCA. A pesquisa caminha no sentido de evidenciar quais são esses benefícios, mostrando como a atividade docente que integra as TDs ao currículo escolar pode contribuir para promover a aprendizagem e efetivar inclusão da escola na Cultura Digita.

Podemos destacar, também, o aspecto positivo da socialização de ideias que é possibilitada pelo UCA. As reflexões do professor sobre a sua prática docente e as tomadas de consciência dos alunos quanto a sua apropriação tecnológica e demais aprendizagens - desde a proposição de um PA até as suas conclusões -, ilustram uma forma construtivista de aprendizagem por cooperação.

Da mesma forma, a mobilização dos alunos com o UCA tornou possível observar um maior envolvimento individual e coletivo com o processo de aprendizagem de cada estudante. Nesse sentido, observa-se, por exemplo, a tomada de consciência do professor sobre o processo de aprender dos alunos, aliado as suas dúvidas, certezas e curiosidades.

Por fim, fica o convite a experimentar as potencialidades propiciadas pelo uso cooperativo das Tecnologias Digitais na escola, em especial através do desenvolvimento de Projetos de Aprendizagem.

\footnotetext{
Notas

${ }^{1}$ Para realizar a comparação entre os conceitos aprendidos pelos alunos e uma possível listagem de conteúdos tradicionalmente aceita, o autor criou um currículo síntese de matemática para a série escolar investigada, tendo como base os Parâmetros Curriculares Nacionais, livros didáticos de matemática, orientações da Secretaria Municipal de Educação de São Leopoldo e planos de estudo de matemática utilizados na escola em estudo.

${ }^{2}$ Informações completas sobre o $\quad$ programa disponíveis em $\langle$ www.uca.gov.br/institucional/projeto.jsp $\rangle$. Acesso em: 26 mar. 2012.

${ }^{3}$ No Rio Grande do Sul, a coordenação do curso de formação de professores encontra-se sob a responsabilidade do Laboratório de Estudos Cognitivos (LEC) da UFRGS, em parceria com as secretarias de educação locais - representadas por seus NTEs e NTms - e grupos de pesquisadores-formadores ligados aos Programas de Pós-Graduação da Unisinos e da UCS.

${ }^{4}$ Fazem parte do programa escolas urbanas e rurais, comunidades em contextos sociais, de infraestrutura e de políticas pedagógicas variadas.
} 


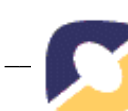

${ }^{5}$ Retomamos aqui o termo midiático, definido por Martinand (1992), para falar dos efeitos das mídias na transposição didática (Alava, 2002, p. 61).

${ }^{6} \mathrm{O}$ fórum pertence à formação de professores em serviço das escolas participantes do projeto UCA/RS. Encontra-se no ambiente virtual de aprendizagem E-proinfo.

\section{Referências Bibliográficas}

AIRES, J.A. Integração Curricular e Interdisciplinaridade: sinônimos? Educação e Realidade, Porto Alegre, v. 36, n.1, p. 215-230, jan./abr., 2011. Disponível em: http://www.ufrgs.br/edu_realidade. Acesso: 07.10.2011

ALAVA, S. (org.). Ciberespaço e formação abertas: rumo a novas práticas educacionais. Tradução de Fátima Murad. Porto alegre: Artmed, 2002.

BONA, A.S. Portfólio de Matemática: um instrumento de análise do processo de aprendizagem. Porto Alegre: PPGEnsiMat/UFRGS, 2010. 402p. Dissertação.

BONA, A.S., FAGUNDES, L. C., BASSO, M. V. A. Reflexões sobre a educação a distância na educação matemática. In: RENOTE - Revista Novas Tecnologias na Educação, v. 9, n. 1, 2011.

FAGUNDES, L.C. (org.). Informática e o Processo de Aprendizagem. Psicologia: Reflexão e Crítica, v. 5, n. 1, 1992. Porto Alegre: Instituto de Filosofia e Ciências Humanas da UFRGS, 1992

FAGUNDES, L.C., SATO, L.S., MAÇADA, D.L. Aprendizes do futuro: as inovações começaram! MEC, 1999. Disponível em: <http://ww.dominiopublico.gov.br/download/ texto/me003153.pdf>. Acesso em: 26 mar. 2012.

HOFFMANN, D S., FAGUNDES, L.C. Cultura Digital na Escola ou Escola na Cultura Digital? In: RENOTE - Revista Novas Tecnologias na Educação, v. 6, n. 1, 2008.

MATTOS, E.B.V. Construção de conceitos de matemática via Projetos de Aprendizagem. Porto Alegre: PPGEnsiMat/UFRGS, 2010. 245p. Dissertação.

NEVADO, R., CARVALHO, M. J.S., MENEZES C.S. Educação a distancia mediada pela internet: uma abordagem interdisciplinar na formação de professores em serviço. In: __ (org.) Aprendizagem em rede na educação a distância: estudos e recursos para a formação de professores. Porto Alegre: Ricardo Lenz, 2007.

PIAGET, J. Estudos Sociológicos. Rio de Janeiro: Forense, 1973.

PIRES, C.M.C. Formulações basilares e reflexões sobre a inserção da Matemática no currículo, visando a superação do binômio máquina e produtividade Educ. Mat. Pesqui., São Paulo, v. 6, n. 2, pp. 29-61, 2004 Disponível em: http://revistas.pucsp.br/ index.php/emp/article/view/4688 Acesso em: 25.03.11

PRADO, M.E.B.B. Pedagogia de projetos: fundamentos e implicações. In: ALMEIDA, M. E. B. (org.); MORAN, J. M. (org.). Integração das Tecnologias na Educação. SEED/MEC 2005.

SOARES, E.M.S., VALENTINI, C.B., PESCADOR, C.M. Digital Literacy and construction of meaning.. In Proceedings of the 15th Biennial of the International Study Association on Teachers and Teaching (ISATT), Back to the Future: Legacies, Continuities and Changes in Educational Policy, Practice and Research, Braga, University of Minho. Braga (PT): Centro de Investigação em Educação (CIEd), 2011. p.872-877. 